\title{
COMPARING THE OUTCOMES OF HORIZONTAL AND VERTICAL INTEGRATION OF SUSTAINABILITY CONTENT INTO ENGINEERING CURRICULA USING CONCEPT MAPS
}

\author{
Elise Barrella $a^{1,3}$ and Mary Katherine Watson ${ }^{2}$ \\ ${ }_{1}^{1}$ Department of Engineering, James Madison University, United States \\ ${ }^{2}$ Department of Civil and Environmental Engineering, The Citadel, United States \\ ${ }^{3}$ barrelem@jmu.edu
}

\begin{abstract}
The goal of this project was to compare the conceptual sustainability knowledge of students at two institutions that differ in their approaches of integrating sustainability into curricula. One institution is a research-intensive university that has implemented a sustainability-focused course (vertical integration), and the second is a teaching-focused university that has woven sustainability into a variety of classes across its curriculum (horizontal integration). At both institutions, students beginning their capstone design experience created concept maps (cmaps) on the focus question: "What is sustainability?" Structure of student knowledge was analyzed using the traditional cmap scoring method, while specific content was evaluated using word clouds. Results support that students engaging in the curriculum with horizontal integration demonstrated broader, deeper, and more connected knowledge than students enrolled in the vertically-integrated curriculum. Furthermore, students participating in the horizontallyintegrated curriculum demonstrated a more balanced understanding of sustainability, with the oftenneglected social dimension being significantly represented in their cmaps, as compared to students from the vertically-integrated curriculum. Economic sustainability was a common weakness.
\end{abstract}

\section{INTRODUCTION}

\subsection{Curricular Reform Strategies}

For sustainable engineering to effectively contribute to global sustainability, engineering curricula must be updated to properly train sustainability-conscious engineers. Two common methods for effective incorporation of sustainability concepts into university curricula include horizontal and vertical integration. Horizontal integration is a strategy where sustainability concepts are incorporated into several courses across a curriculum, while vertical integration involves the addition of new sustainability courses into an existing curriculum (Ceulemans and De Prins 2010). Dissemination of a new course with sustainability content is essential for teaching students about fundamental concepts and principles related to sustainability (Peet and Mulder 2004). However, vertical integration alone may be insufficient because only teaching students about sustainability separate from core engineering concepts does not encourage them to incorporate sustainability into their professional designs and practices (Peet and Mulder 2004). Rather, integration of sustainability into existing courses may aid students in viewing sustainability in a systemic and holistic manner by demonstrating how sustainability and technical content can be blended to create sustainable designs (Peet and Mulder 2004, Ceulemans and De Prins 2010).

\subsection{Sustainability Assessments}

Cmaps are innovative assessment tools that can be used to assess student sustainability understanding. Cmaps are student-generated graphical tools for organizing knowledge in which concepts related to a particular knowledge domain are directionally connected using descriptive linking lines (Novak and Canas 2006). Students are provided with a focus question and asked to transcribe their internal knowledge into a cmap that can be easily reviewed (Ruiz-Primo 2000). Thus, cmaps allow students to explicitly reveal knowledge content, while also demonstrating how that content is mentally organized. Sustainability is a rapidly-evolving and complex knowledge domain, in which highly interconnected economic, environmental, social, temporal, and spatial concepts are very important. As a result, concept-map-based 
assessment tools are ideal for identifying concepts that students associate with sustainability, as well as quantifying the interrelationships between sustainability dimensions. However, practical methods for scoring cmaps are needed before concept-map-based assessment tools are widely applied (e.g., Besterfield-Sacre et al. 2004).

\subsection{Project Scope}

The goal of this project was to compare the impact of different strategies for integrating sustainability into undergraduate engineering curricula on student sustainability knowledge. The Georgia Institute of Technology (GT) has added a sustainability-focused course into their curriculum (vertical integration), while efforts to add sustainability concepts into existing courses (horizontal integration) is left to the discretion of the instructor. In contrast, James Madison University (JMU) has included sustainability and sustainable design as key elements that are woven throughout their interdisciplinary engineering curriculum. Concept maps created by upperclassmen at these two differing institutions were collected and analyzed to address the following research questions: (1) How do differences in sustainability integration strategies impact the structure of student knowledge? (2) What are the differences in the knowledge content of students from institutions with different sustainability curricula?

\section{BACKGROUND INFORMATION: CONCEPT MAPS}

Concept maps (cmaps) can be used to capture the structure and content of student knowledge in a given domain. Several scoring methods are available to extract data from cmaps. As theoretically-grounded tools, cmaps are used as assessment strategies in a variety of fields, including sustainable engineering.

\subsection{Function and Structure}

Cmaps are graphical tools for organizing knowledge. Construction of a cmap is completed by enclosing concepts related to a central topic in boxes and using connecting lines, as well as linking phrases, to depict relationships between concepts (Novak and Canas 2006). The basic unit of a cmap is a proposition, which includes two concepts joined by a descriptive linking line. Propositions that include the cmap topic define the map hierarchies, and the level of hierarchy is defined by the number of concepts in the hierarchy. Cross-links, which are important for depicting connectedness, are descriptive linking lines that create propositions by joining two concepts from different map hierarchies (Watson et al. 2014).

\subsection{Theoretical Bases}

Use of cmaps is supported by cognitive psychological research in the area of semantic memory theory. Semantic memory refers to an organized database of concept-based knowledge, such as meanings, understandings, and images (Tulving 1972). Semantic memory theory posits that knowledge networks are formed by creating directed links between related concepts. Some researchers have proposed that networks are structured hierarchically with broad concept categories being divided into more specific subcategories (Collins and Quillian 1970), while other researchers have rejected this assumption (e.g., RuizPrimo 2000). Nevertheless, interconnectedness within the structure is an important network characteristic, since it increases one's ability to access concepts (Turns, Atman, and Adams 2000) and is a key feature that differentiates expert and novice knowledge frameworks (Ruiz-Primo 2000). Since cmaps mimic the structure of internal semantic networks, student-generated constructs may be used to infer a student's domain understanding.

\subsection{Use as Assessment Tools}

Cmaps are an alternative to traditional assessment tools for characterizing knowledge content and structure. One significant challenge in using cmaps as assessment tools is identification of a robust scoring method (Besterfield-Sacre et al. 2004). Several scoring methods, including the commonly-used traditional approach, have been summarized elsewhere (Watson et al. 2014).

The traditional method (Besterfield-Sacre et al. 2004) involves quantifying the number of components in each cmap. For instance, the number of concepts, the number of hierarchies and highest level of 
hierarchy, and the number of cross-links are used to determine sub-scores for knowledge breadth, depth, and connectedness, respectively (Table 1). Some authors advocate for sub-scores being condensed into one metric using weightings for component sub-scores. For instance, Novak and Gowin (1998) propose that each proposition and example should receive 1 point, each level of hierarchy should receive 5 points, and each cross-link should receive 10 points. Alternatively, Bayram (1995) assigned one point for each proposition and cross-link, while each hierarchy was multiplied by its level (e.g., 2 points for a hierarchy with two levels). Novak and Gowin (1998) and Bayram (1995) each calculate the overall cmap score as the sum of weighted points. In contrast, Markham et al. (1994) argue that component sub-scores are more valuable when analyzed independently. Nevertheless, component-level scoring can provide an objective method for quantitatively scoring cmaps.

Table 1. Rubric for traditional cmap scoring approach (Besterfield-Sacre et al. 2004).

\begin{tabular}{|c|c|c|}
\hline Knowledge Breadth & Knowledge Depth & Knowledge Connectedness \\
\hline $\begin{array}{l}\text { - The number of concepts } \\
\text { included in the cmap is } \\
\text { counted. } \\
\text { - No consideration given to } \\
\text { quality or correctness of } \\
\text { concepts. }\end{array}$ & $\begin{array}{l}\text { - The number of } \\
\text { hierarchies included in } \\
\text { the cmap is counted. } \\
\text { - The highest level of } \\
\text { hierarchy is recorded. }\end{array}$ & $\begin{array}{l}\text { - The number of cross-links, which create } \\
\text { propositions using concepts from different } \\
\text { hierarchies, is counted. } \\
\text { - No consideration given to quality or } \\
\text { correctness of cross-links. }\end{array}$ \\
\hline
\end{tabular}

\subsection{Applications in Sustainability Education}

Several authors have used cmaps to characterize student sustainability understanding. Segalàs et al. (2008) investigated the effectiveness of six sustainability courses by comparing student cmaps before and after course delivery (Segalàs, Ferrer-Balas, and Mulder 2008). Evaluation of cmaps revealed that complexity of cmaps resulting from courses employing constructive and community-based pedagogies was higher than from courses using more traditional instructional strategies (Segalàs, Ferrer-Balas, and Mulder 2010). Similarly, Borrego et al. (2009) analyzed cmaps before and after a green engineering course using the holistic scoring method and found that the comprehensiveness, correctness, and organization of student maps increased after course delivery. Use of cmaps as assessment tools were also used to monitor student learning in capstone engineering courses (Watson et al. 2013). Thus, cmaps are beginning to be applied as tools for studying student sustainability knowledge.

\section{RESEARCH METHODS}

\subsection{Student Populations}

Student sustainability knowledge was investigated at GT and JMU for students beginning their capstone design experiences. Seniors ( $4^{\text {th }}$ year) in Civil and Environmental Engineering (CEE) at GT were recruited to construct cmaps documenting their sustainability knowledge. GT has taken a largely vertical integration approach to incorporating sustainability into the CEE curricula, with primary exposure occurring in a required junior-level ( $3^{\text {rd }}$ year) systems course. For comparison, juniors enrolled in an interdisciplinary engineering program at JMU were also invited to construct sustainability cmaps. JMU has embraced a horizontal integration approach, as sustainability is an integral part of their entire curriculum from the freshman introductory course through the two-year capstone design experience. Most of the students in the JMU sample had not yet completed the two required senior-level sustainability science and lifecycle courses. Additional information on the curricula at GT (Watson, Noyes, and Rodgers 2013) and JMU (Nagel et al. 2013, Pierrakos et al. 2008) are available.

\subsection{Concept Mapping Assessment}

The concept mapping assessment was conducted as outlined by Watson et al. (2014). Before completion of the sustainability concept mapping task, students participated in a brief concept mapping workshop to familiarize them with the construction of cmaps using Cmap Tools. Afterward, students were asked to create a concept map on the focus question: "What is sustainability?". Students were provided with up to three hours to complete their cmaps at GT, although most students were finished after thirty minutes. 
Students at JMU were provided with approximately thirty minutes to construct cmaps and all students finished within that timeframe.

\subsection{Concept Map Analysis}

Three judges were trained to use the traditional scoring method. Judges practiced scoring approximately 10 cmaps and discrepancies were discussed to promote future interrater reliability. Krippendorf's alphas for the training sessions were at least 0.67 , which is appropriate for exploratory research (Krippendorff 2004). Further details on scoring calibration are available (Watson et al. 2014).

After scoring calibration, judges scored cmaps generated by JMU and GT students. Two judges scored each submission. First, judges individually quantified traditional scoring parameters. Inter-rater reliability, based on Krippendorff's alpha, was deemed to be acceptable (Krippendorff 2004) for all parameters (Table 2). Discrepancies in scores were discussed by the judges and consensus scores were used in all subsequent statistical analyses. Since data was determined to be non-normal (Shapiro-Wilk test), nonparametric Kruskal-Wallis tests were used to compare cmap scores based on institution. Significant relationships were identified for $p \leq 0.05$.

Table 2. Inter-rater reliability for cmap scoring.

\begin{tabular}{lcc}
\hline \multirow{2}{*}{ Parameter } & \multicolumn{2}{c}{ Krippendorff's Alpha } \\
\cline { 2 - 3 } Number of Concepts $(\mathrm{NC})$ & Vertical Integration (GT) & Horizontal Integration (JMU) \\
Number of Hierarchies (NH) & 0.999 & 0.999 \\
Highest Hierarchy $(\mathrm{HH})$ & 0.999 & 0.973 \\
Number of Cross-Links (NCL) & 0.980 & 0.845 \\
\hline
\end{tabular}

In order to compare the students' depth and breadth of sustainability knowledge, the content of cmaps was analyzed using word clouds, a strategy used by others for content analysis (Huynh et al. 2013). Concepts were extracted from the cmaps and used to generate word clouds with Wordle ${ }^{\mathrm{TM}}$. For consistency, the extracted concepts were not modified in any way (e.g., spelling could have been corrected). Further, default settings were used for language (remove numbers, remove common English words, leave words as spelled) and a horizontal layout was selected for both GT and JMU word clouds. For each word cloud, the frequency of concepts was tallied using the show count function. Given the large number of words, only concepts with a count greater than five were recorded. Concepts were then coded in accordance with a four pillar conceptualization of sustainable engineering - economic, environmental, social, and technical pillars. Concepts that did not directly match one of the four categories or could easily be coded as more than one pillar were coded as "other". The resultant word clouds and content themes are described in Section 4.2.

\section{RESULTS}

A study was conducted to compare sustainability cmaps between student populations at institutions which initiated either horizontal (JMU) or vertical (GT) integration of sustainability content into undergraduate curricula. The structure of cmaps was analyzed using the traditional scoring approach, while cmap content was examined using word clouds.

\subsection{Traditional Cmap Scores}

The structure of JMU students' cmaps was more complex than those constructed by GT students (Table 3). Specifically, knowledge breadth was greater for JMU students than for GT students, given that the median number of concepts was 23 and 12, respectively $(p \leq 0.001)$. Similarly, JMU students demonstrated more substantial knowledge depth than did GT students, with the median highest hierarchy being 4 versus 3 for each group, respectively $(p \leq 0.001)$. Even still, JMU students prepared cmaps that were significantly more interrelated in structure than those submitted by GT students, with the median number of cross-links recorded as 4 versus 2, respectively. Due to the broader, deeper, more inter-related structure of JMU cmaps, overall scores were nearly twice as high (Med $=120.98)$ as for GT cmaps (Med $=61.35)(p \leq 0.001)$. 
Table 3. Comparison of traditional scores across institutions.

\begin{tabular}{|c|c|c|c|c|c|c|}
\hline \multirow[t]{2}{*}{ Parameter } & \multicolumn{2}{|c|}{$\begin{array}{l}\text { Horizontal Integration (JMU) } \\
\qquad(n=86)\end{array}$} & \multicolumn{2}{|c|}{$\begin{array}{c}\text { Vertical Integration (GT) } \\
(n=93)\end{array}$} & \multicolumn{2}{|c|}{ Kruskal-Wallis Test } \\
\hline & Mean Rank & Median & Mean Rank & Median & $x^{2}(1)$ & $p$ \\
\hline Number of Concepts & 125.03 & 23 & 57.61 & 12 & 75.81 & $0.000^{\star \star \star}$ \\
\hline Number of Hierarchies & 92.10 & 4 & 88.05 & 3 & 0.28 & 0.597 \\
\hline Highest Hierarchy & 114.14 & 4 & 67.68 & 3 & 37.73 & $0.000^{* * *}$ \\
\hline Number of Cross-links & 107.80 & 4 & 73.54 & 2 & 19.92 & $0.000^{* * *}$ \\
\hline Total Score & 120.98 & 91.5 & 61.35 & 43.0 & 59.17 & $0.000^{* * *}$ \\
\hline
\end{tabular}

\subsection{Content Analysis}

Visual and thematic analysis of the word clouds allowed qualitative comparisons of depth and breadth of content coverage (Figures 1-2 and Table 4). Visually, the word clouds illustrate a clear environmental theme in the GT concept maps, which is often expected of students' sustainability knowledge (e.g., Segalàs, Ferrer-Balas, and Mulder 2010). JMU concept maps showed a more balanced conceptualization with greater emphasis on the social pillar.

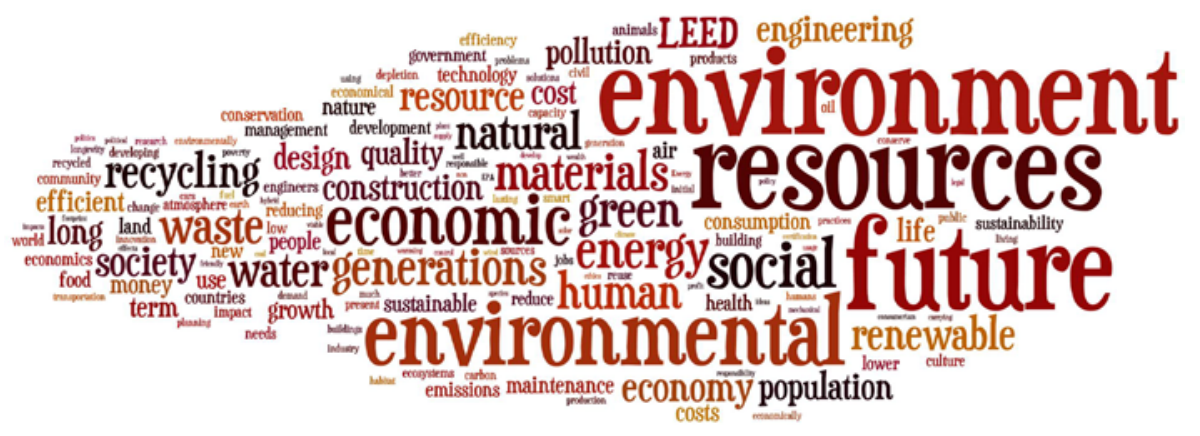

Figure 1. GT Sustainability World Cloud

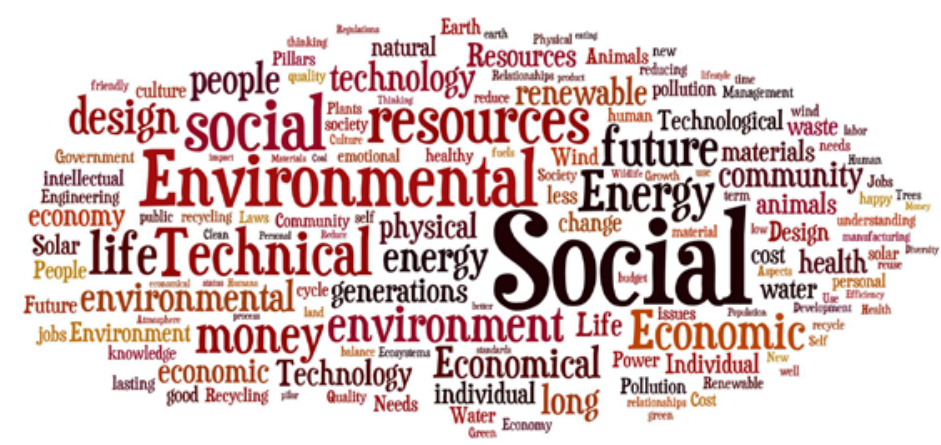

Figure 2. JMU Sustainability Word Cloud

Table 4 shows that GT students demonstrated unbalanced representations of sustainability with environmental concepts dominating the other categories in terms of both diversity of concepts and frequency. From JMU concept maps, the social dimension demonstrated the greatest diversity of terms amongst the four categories, although environmental concepts were included with greater frequency (30\% versus $27 \%$ for social). For both GT and JMU concept maps, the economic dimension was least well represented, both in terms of number of concepts within that category ( 8 and 6 respectively) and frequency ( $11 \%$ and $12 \%$ respectively). 
Table 4. Comparison of Concept Map Content from Word Clouds

\begin{tabular}{l|ccc|ccc}
\hline \multirow{2}{*}{ Dimension } & \multicolumn{3}{|c|}{ Vertical Integration (GT) } & \multicolumn{3}{c}{ Horizontal Integration (JMU) } \\
\cline { 2 - 7 } & $\begin{array}{l}\text { \# Distinct } \\
\text { Concepts }\end{array}$ & $\begin{array}{c}\text { Frequency } \\
\text { (Count) }\end{array}$ & $\begin{array}{c}\text { Frequency } \\
\text { (\% of total) }\end{array}$ & $\begin{array}{c}\text { \# Distinct } \\
\text { Concepts }\end{array}$ & $\begin{array}{c}\text { Frequency } \\
\text { (Count) }\end{array}$ & $\begin{array}{c}\text { Frequency } \\
\text { (\% of total) }\end{array}$ \\
\hline Econ & 8 & 99 & $11 \%$ & 6 & 119 & $12 \%$ \\
Env & 21 & 370 & $40 \%$ & 16 & 312 & $30 \%$ \\
Other & 13 & 166 & $18 \%$ & 17 & 175 & $17 \%$ \\
Soc & 13 & 151 & $17 \%$ & 21 & 284 & $27 \%$ \\
Tech & 13 & 129 & $14 \%$ & 10 & 144 & $14 \%$ \\
\hline
\end{tabular}

\section{DISCUSSION}

\subsection{Structure of Student Knowledge}

Examining cmap structure clearly shows that students completing a curriculum with horiztonal integration of sustainability content displayed broader, deeper, and more inter-connected sustainability knowledge, as compared to students enrolled in a vertically-integrated curriculum. This finding aligns with previous purblications that underscore the importance of blending sustinability content with existing engineering coursework (Peet and Mulder 2004, Ceulemans and De Prins 2010). Examining knowledge breadth, a group of sustainability experts was reported to include an average of 19.8 concepts in their sustainability cmaps (Coral 2009), as compared to medians of 12 and 23 for GT and JMU students, respectively (Table 3). Thus, JMU students demonstrated more expert-like knowledge breadth than GT students. Furthermore, the greater level of concept connectedness displayed by JMU students is especially significant, since connectedness of knowledge is known to increase student ability to access concepts and is a key feature that differentiates expert and novice knowledge frameworks (Turns, Atman, and Adams 2000, Ruiz-Primo 2000). Overall, data from the current and previous studies suggest that horizontal integration has a positive impact on students' sustainability knowledge networks.

\subsection{Content of Student Knowledge}

Examining word clouds suggests that horizontal integration of sustainability into undergraduate curricula may encourage development of more balanced sustainability knowledge frameworks, as compared to vertical integration. Notably, "environment/al" was frequently represented in all student cmaps, although students from JMU clearly included the term "social" more often than students from GT (Figures 1-2). Further, JMU students distinguished between individual and community dimensions of the social pillar. Prior research on students' conceptual understanding of sustainability has overwhelmingly suggested that students often emphasize the environmental dimension of sustainability, while largley neglecting social aspects (e.g., Watson et al. 2014). Interestingly, one study has proposed that social considerations, especially related to end-user safety and well-being, are often evident in student designs, even if cmaps demonstrate little knowledge of social sustainability (e.g., Watson et al. 2013). Authors cite that students may not recognize that many routine aspects of engineering design promote social sustainability, at least to some extent. Consequently, perhaps integration of sustainability content into the unique sequence of design courses at JMU contributed to students awareness of social aspects of sustainability. It is important to note that the majority of JMU students participated in a client-based sophomore design project and are exposed to identifying stakeholder needs and impacts over a project's lifecycle during that course experience. The "equity" dimension of social sustainability remains a weak area for students' conceptualizations and applications of sustainability knowledge, and the content of cmaps in this study did not indicate otherwise. Likewise, economic analysis could be further developed to enable appropriate and realistic trade-offs amongst the four dimensions. Nevertheless, the increased balance among sustainability dimensions demonstrated by JMU students is desirable, since promoting sustainability inherently requires an understanding of all inter-related dimensions (Davidson et al. 2007).

\subsection{Limitations and Implications for Research}

Several limitations are inherent in the design of this project. Foremost, only one institution exemplifying each integration strategy was investigated. Vertical and horizontal integration are two very broad 
strategies that can encompass a variety of educational interventions. For instance, a program with a different vertically-integrated sustainability course (e.g., more comprehensive, more active, emphasis on different topics) may have proved to be more or less effective than the GT case. Consequently, investigation of integration strategies across multiple institutions may provide more generalizable results.

Second, there were several differences between student groups in the current study that could have contributed to differences in cmap scores, beyond just exposure to different integration strategies. Specifically, students were in different stages of their academic careers (juniors at JMU and seniors at GT) and engaged in a non-discipline specific curriculum at JMU versus a CEE curriculum at GT. However, student academic development may have actually been more similar than expected, since both groups were entering their first comprehensive, independent design experience. Even still, junior JMU students demonstrated more comprehensive sustainability knowledge than senior GT students, despite completing fewer semesters of the prescribed curriculum. Despite these differences in student samples, it is expected that significant differences in student sustainability knowledge demonstrated in this study is due to inherent differences in the curricula of the two institutions. The methods and results of this study do not address how students' conceptualizations of sustainability translate to performance on the capstone design projects, which is an area for future research.

\section{CONCLUSIONS}

A study was conducted to evaluate the efficacy of horizontal versus vertical integration of sustainability content into undergraduate engineering curricula. Cmaps were collected from students in a horizontallyintegrated, interdisciplinary engineering program, as well as a vertically-integrated, CEE program. The structure of student knowledge was analyzed using the traditional scoring approach, while specific content was evaluated using word clouds. The following conclusions were made based on the results:

1. Horizontal integration resulted in student cmaps with greater breadth, depth, and interconnectedness, as compared to vertical integration.

2. Students participating in a horizontally-integrated curriculum demonstrated more balanced understanding of sustainability, including the social dimension, as compared to students from a vertically-integrated program. To some extent, economic sustainability was a weakness of both programs.

Results from this study align with previously-published suggestions that horizontal integration of sustainability is important for student development. If sustainability is only taught in isolation from core engineering fundamentals, then it is possible that students will view sustainability as an afterthought during the design process. Given that current undergraduate students will soon be responsible for local and global development projects that will impact both humans and the environment, it is important to equip them with the knowledge and skills necessary to engage in sustainable design.

\section{Acknowledgement}

This study was supported in part by NSF EEC-1158728, A Contextual Approach to Researching and Teaching Sustainability.

\section{References}

Bayram, S. 1995. "The Effectiveness of Concept and Software Mapping for Representing Student Data and Process Schema in Science."Masters, University of Pittsburgh.

Besterfield-Sacre, M., J. Gerchak, M.R. Lyons, L.J. Shuman, and H. Wolfe. 2004. "Scoring concept maps: An integrated rubric for assessing engineering education." Journal of Engineering Education 93 (2):105-115.

Borrego, M., C.B Newswander, L.D. McNair, S. McGinnis, and M.C. Paretti. 2009. "Using concept maps to assess interdisciplinary integration of green engineering knowledge." Advances in Engineering Education 1 (3):1-26. 
Ceulemans, K., and M. De Prins. 2010. "Teacher's manual and method for SD integration in curricula." Journal of Cleaner Production 18 (7):645-651.

Collins, A.M., and M.R. Quillian. 1970. "Facilitating retrieval from semantic memory: The effect of repeating part of an inference." Acta Psychologica 33:304-314.

Coral, J.S. 2009. "Dissertation: Engineering Education for a Sustainable Future." Universitat Politecnica de Catalunya.

Davidson, Cliff I., H. Scott Matthews, Chris T. Hendrickson, Michael W. Bridges, Braden R. Allenby, John C. Crittenden, Yongsheng Chen, Eric Williams, David T. Allen, Cynthia F. Murphy, and Sharon Austin. 2007. "Viewpoint: Adding sustainability to the engineer's toolbox: A challenge for engineering educators." Environmental Science \& Technology 41 (14):4847-4849. doi: 10.1021/es072578f.

Huynh, N., J.M. Caicedo, C.E. Pierce, and J.W. Gantt. 2013. "Combining In-Class Design Problems and EFFECTs to Stimulate Critical Thinking Skills " American Society for Engineering Education Annual Conference and Exposition, Atlanta, GA.

Krippendorff, K. 2004. Content Analysis: An Introduction to its Methodology. 1nd ed. Thousand Oaks, CA: Sage Publications Inc.

Markham, K.M., J.J. Mintzes, and M.G. Jones. 1994. "The concept map as a research and evaluation tool: Further evidence of validity." Journal of Research in Science Teaching 31 (1):91-101.

Nagel, R., K. Gipson, J. Spindel, and E. Barrella. 2013. "Blending Sustainable Design, Systems Thinking, and Engineering Science Concepts in an Introductory Engineering Course." American Society for Engineering Education Annual Conference and Exposition, Atlanta, GA, June 23-26, 2013.

Novak, J.D. 1998. Learning, Creating, and Using Knowledge: Concept Maps as Facilitative Tools in Schools and Corporations. Mahwah, NJ: Lawrence Erlbaum Associates.

Novak, J.D., and A.J. Canas. 2006. The Theory Underlying Concept Maps and How to Construct Them. Institute for Human and Machine Cognition.

Peet, D.J., and K.F. Mulder. 2004. "Integrading SD into engineering courses at the Delft University of Technology." International Journal of Sustainability in Higher Education 5 (3):278-288.

Pierrakos, O., R. Kander, E. Pappas, and R. Prins. 2008. "An innovative engineering curriculum at James Madison University: Transcending Disciplinary Boundaries through Innovative Problem Based Learning Practices." American Society of Mechanical Engineers International Mechanical Engineering Congress \& Exposition, Boston, MA.

Ruiz-Primo, A. 2000. "On the use of concept maps as an assessment tool in science: What we have learned so far " Revista Electrónica de Investigación Educativa 2 (1):29-53.

Segalàs, J., D. Ferrer-Balas, and K. F. Mulder. 2008. "Conceptual maps: measuring learning processes of engineering students concerning sustainable development." European Journal of Engineering Education 33 (3):297 - 306.

Segalàs, J., D. Ferrer-Balas, and K. F. Mulder. 2010. "What do engineering students learn in sustainability courses? The effect of the pedagogical approach." Journal of Cleaner Production 18 (3):275-284.

Tulving, E. 1972. "Episodic and Semantic Memory." In Organization of Memory, edited by E. Tulving and W. Donaldson. Oxford, England: Academic Press.

Turns, J., C. Atman, and R. Adams. 2000. "Concept maps for engineering education: a cognitively motivated tool supporting varied assessment functions." IEEE Transactions on Education 43 (2).

Watson, M.K., E. Barrella, T. Wall, C. Noyes, and M.O. Rodgers. 2013. "Development and Application of a Sustainable Design Rubric to Evaluate Student Abilities to Incorporate Sustainability into Capstone Design Projects." American Society for Engineering Education Annual Conference and Exposition, Atlanta, GA.

Watson, M.K., J.G. Pelkely, C. Noyes, and M.O. Rodgers. 2014. "Use of Concept Maps to Assess Student Sustainability Knowledge." American Society for Engineering Education Annual Conference and Exposition, Indianapolis, IN.

Watson, M.K., C. Noyes, and M.O. Rodgers. 2013. "Student perceptions of sustainability education in civil and environmental engineering at the Georgia Institute of Technology." Journal of Professional Issues in Engineering Education and Practice 139 (3):235-243. 